\title{
Application of ultrasound elastography in the evaluation of muscle strength in a healthy population
}

\author{
Xinyi Tang, Liyun Wang, Ruiqian Guo, Songya Huang, Yuanjiao Tang, Li Qiu \\ Department of Medical Ultrasound, West China Hospital of Sichuan University, Chengdu, China \\ Correspondence to: Li Qiu. Department of Medical Ultrasound, West China Hospital of Sichuan University, No.37 Guoxue Alley, Chengdu, China. \\ Email: wsqiuli@vip.126.com.
}

Background: To investigate the validity of shear wave elastography (SWE) for the evaluation of muscle strength compared with isokinetic muscle testing, and to assess the influence of demographic factors such as height, weight, and body mass index (BMI) on the shear wave velocity (SWV).

Methods: Sixty healthy volunteers were consecutively enrolled. SWE was used to measure the SWV of the right quadriceps femoris in a relaxed position, in a tensive position, and under loads of 1 and $2 \mathrm{~kg}$. Muscle strength parameters including peak torque (PT), PT to body weight ratio (PT/BW), and total work (TW) were evaluated using isokinetic muscle testing. The SWV of the rectus femoris in different positions were compared using the Friedman test and the Kruskal-Wallis test, and the SWV and muscle strength parameters were compared between different genders and age groups using the Mann-Whitney U test. Additionally, Spearman's correlation coefficient was used to evaluate the correlation between SWV and muscle strength, as well as the possible effects of height, weight, and BMI on SWV.

Results: As the load increased, the SWV of the rectus femoris increased $(\mathrm{P}<0.001)$. In the relaxed position, there was no significant correlation between the SWV and the results of isokinetic muscle testing. With increasing load, the SWV and the results of isokinetic muscle testing were not significantly correlated $(\mathrm{r}=-0.256--0.392, \mathrm{P}<0.05)$. In the $1 \mathrm{~kg}$ load position, height and weight were not significantly correlated with SWV $(\mathrm{r}=-0.261-0.393, \mathrm{P}<0.05)$. In the relaxed position, there were no significant differences in the maximum, minimum, or mean SWV of the rectus femoris between different genders and age groups $(\mathrm{P}>0.05)$. However, under a $1 \mathrm{~kg}$ load, the maximum, minimum, and mean SWV of the females in this study were significantly higher than those of the males $(4.49 \pm 0.60 v s .3 .98 \pm 0.68 \mathrm{~m} / \mathrm{s} ; 2.55 \pm 0.61 v s .2 .20 \pm 0.63 \mathrm{~m} / \mathrm{s}$; and $3.51 \pm 0.60$ vs. $3.06 \pm 0.58 \mathrm{~m} / \mathrm{s} ; \mathrm{P}=0.003,0.028$, and 0.004 , respectively). Furthermore, there were significant differences in the maximum and mean velocities between the groups aged 20-34 and 35-60 years $(4.11 \pm 0.62$ vs. $4.47 \pm 0.70 \mathrm{~m} / \mathrm{s} ; 3.17 \pm 0.53$ vs. $3.52 \pm 0.69 \mathrm{~m} / \mathrm{s} ; \mathrm{P}=0.045$ and 0.044 , respectively).

Conclusions: Ultrasound elastography (UE) shows potential for the measurement of muscle strength. The SWV of muscles demonstrate an increasing trend with the increase of impedance. Additionally, age and gender have a significant effect on SWV, while the effects of height, weight, and BMI require further investigation.

Keywords: Isokinetic muscle testing; shear wave elastography (SWE); shear wave velocity (SWV); muscle strength-based parameters

Submitted Mar 13, 2020. Accepted for publication Jul 22, 2020.

doi: 10.21037/qims-20-439

View this article at: http://dx.doi.org/10.21037/qims-20-439 


\section{Introduction}

Muscle strength and muscle stiffness play critical roles in the assessment of motor function (1). Degeneration of muscle fibers and infiltration of adipose tissue in muscle tissue often manifest as changes in muscle stiffness and changes of muscle strength and muscle tension (2-4). At the same time, muscles provide traction through the contraction of muscle fibers, and the contraction of muscle fibers reflects changes in muscle stiffness at the macro level $(5,6)$. Based on these physiological and pathophysiological features, we hypothesized that muscle stiffness can reflect the contractile ability of muscles and is related to muscle strength.

Clinically, a preliminary impression of muscle strength, joint mobility, and muscle stiffness can be obtained through palpation and physical examination (7); although, this qualitative or semi-quantitative examination method is subjective and is susceptible to the personal experience of examiners. Magnetic resonance elastography (MRE) can be used to quantitatively measure muscle stiffness (8-10); however, this method is relatively complicated and expensive, and can only be performed in the supine position. It cannot be performed in patients with claustrophobia or metal implants. These limitations significantly restrict its application. Despite isokinetic muscle testing currently being the gold standard for the assessment of muscle strength and muscle function (11), it also has a number of limitations. For example, it requires a complicated operation procedure, and cannot be performed in patients with impaired mobility or patients who cannot hear or understand instructions. Due to the large size and cost of the machine, small-to-medium-sized hospitals cannot universally apply this technology to evaluate muscle strength. Therefore, a safe, reliable, simple, and accurate quantitative method for evaluating muscle strength is needed.

Over the last decade, musculoskeletal ultrasound has developed rapidly and has been extensively applied in clinical practice. High-frequency ultrasound (HFUS), for instance, can distinguish fine structures and echo changes of superficial tissues, and it can also accurately locate and qualitatively diagnose intramuscular lesions (12-14). Ultrasound elastography (UE), a new technique for measuring the stiffness of biological tissues, is used to examine the stiffness of organs and tissues, such as the liver, kidney, thyroid, and breast (15-18). Certain ultrasound parameters, such as muscle thickness, muscle cross-sectional area, and pennation angle, have been utilized in previous studies, and can be used to evaluate the size, structure, and contraction ability of muscles (19-21). UE can quantitatively measure the stiffness of muscle tissue at different levels of contraction $(5,22-24)$, indicating that it may be a potential method to quantitatively reflect muscle movement and contraction ability. However, no definite agreement has been reached as to whether the stiffness of muscles at different levels of contraction is related to their motor ability. Therefore, we designed this study to investigate the relationship between these two measures.

At present, UE mainly includes strain elastography (SE), acoustic radiation force impulse imaging (ARFI), and shear wave elastography (SWE). Among them, SWE is an ultrasound technique that was recently developed for the visualization and measurement of tissue stiffness. The ultrasonic sound beam automatically induces acoustic radiation, pushing the tissue to produce mechanical vibrations, thereby generating shear waves that propagate throughout the tissue. The propagation velocity of the shear wave in tissue can be accurately quantified and calculated as follows: $\mathrm{E}=3 \rho \mathrm{C}^{2}$ [E is the elasticity of tissue, $\rho$ denotes the density of tissue, and $\mathrm{C}$ is the the shear wave velocity (SWV)], where the E value, known as Young's modulus, represents the mechanical properties of the tissue $(25,26)$. The harder the tissue, the faster the SWV, and the larger the value of the Young's modulus. However, the application of the above-mentioned formula is typically used for isotropic, elastic, and locally homogeneous tissues, such as the liver, thyroid, or breast. Muscles, tendons, and peripheral nerves, on the other hand, are anisotropic tissues. A number of researchers have pointed out that when using SWE to measure these tissues, the original SWV is more accurate than the Young's modulus value $(11,22,27)$. Therefore, in this study, SWV was selected as the quantitative evaluation parameter of $\mathrm{UE}$.

Because UE requires a relatively static state between the probe and the subject, measuring SWV in real time during body movement is challenging. Therefore, in this study, the subjects were asked to keep the lower limb static against certain resistance while the $S W V$ of the quadriceps femoris was measured, which reflected the extent of isometric contraction of the muscle. We hypothesized that the SWV of the rectus femoris are correlated with the results of isokinetic muscle testing. We also assessed the reliability of SWE for the evaluation of muscle strength compared with isokinetic muscle testing, and verified whether ultrasound can be a potential tool for evaluating muscle strength in the 
future. Lastly, we assessed the influences of factors such as height, weight, and body mass index (BMI) on the SWV. We present the following article in accordance with the STROBE guideline checklist.

\section{Methods}

\section{Study subjects}

Sixty healthy volunteers, who were consecutively recruited at our institution between September 2017 and December 2018, were enrolled in this cross-sectional study. The gender, age, height, weight used to calculate BMI, SWV of the rectus femoris, and muscle strength of the quadriceps femoris of the study subjects were all recorded.

This study was approved by the Ethics Committee of West China Hospital of Sichuan University (Chengdu, China), and was performed in accordance with the Declaration of Helsinki [2013]. The primary inclusion criteria for the healthy volunteers were as follows: (I) aged between 20-60 years old; (II) satisfactory compliance; and (III) limb muscle strength level 5 , as determined by experienced rehabilitation physicians using muscle strength assessment. The exclusion criteria were as follows: (I) pregnancy; (II) a history of local or systemic musculoskeletal disease, rheumatic autoimmune diseases, endocrine or metabolic disorders, nervous system diseases, or other diseases that may lead to abnormal muscle strength; or (III) local inflammation, trauma, scarring, tumors, or a history of surgery. The study subjects were classified into two groups according to their age (the 20-34 age group and the 35-60 age group).

\section{SWE examination}

The sonographic equipment used was the Aixplorer US system (SuperSonic Imagine, Aixen-Provence, France), with an SL 15-4 multifrequency linear transducer. The superficial musculoskeletal setting was selected with the standard default mode of the equipment. The depth was fixed at $4 \mathrm{~cm}$, and the focus was adjusted to the muscular layer.

Consistent with a study by Dubois et al. (28), the rectus femoris muscle of the right side was selected for measurement in the current study. Using palpation, we drew a line, with the middle and lower thirds of the line between the anterior superior iliac spine and the superior margin of the patella. The probe was then placed transversely at the marked site to locate the rectus femoris in the ultrasound image. After locating the thickest site, the probe was rotated parallel to the long axis of the lower extremity. As shown in Figure 1, the SWV of the study subjects were measured at the marked site in four positions: (I) relaxed position: the subject sat on the examination chair, with the upper and lower limbs at approximately $90^{\circ}$. The lower leg was naturally relaxed and sagging, and the subject was asked to stay relaxed. (II) Tensive position: the subject kept their left lower limb relaxed and was asked to extend the knee of the right lower limb to keep the right lower limb straight. (III) $1-\mathrm{kg}$ load position: the subject kept the left lower limb relaxed, and a $1 \mathrm{~kg}$ sandbag was tied to their right external malleolus. The examinee was asked to actively stretch his/ her knees to keep the right lower limb straight. (IV) 2-kg load position: the subject kept the left lower limb relaxed. The first $1-\mathrm{kg}$ sandbag was tied to their right external malleolus, and the second sandbag was tied next to the first one proximally. The examinee was asked to actively stretch their knees to keep the right lower limb straight.

The probe was coated with an appropriate amount of coupling agent. The probe was kept perpendicular to the labeled thigh skin with no pressure applied, and the gap between the skin layer and the probe was filled with a coupling agent. Attention was paid to avoid air bubbles in the coupling agent. After obtaining a standard muscle image, the examiners switched to SWE mode, adjusted the scale to $0-200 \mathrm{kPa}$, and moved the region of interest (ROI) to keep the rectus femoris in the middle of the ROI. When the image was stabilized for approximately 5 seconds, the image was frozen. The diameter of the sampling box (Q-box) was adjusted to $6 \mathrm{~mm}$. When the sampling box was determined, the system automatically displayed the SWV of the rectus femoris muscle, including the maximum SWV (Cmax), average SWV (Cmean), and minimum SWV (Cmin). The measurements were repeated 5 times for each subject, and the average values were calculated and recorded in $\mathrm{m} / \mathrm{s}$.

\section{Isokinetic muscle testing}

The German ISOMED-2000 isokinetic muscle strength test system was adopted. After conventional calibration, flexion and extension strengths of the bilateral knee joints were measured, first on the right side and then on the left side. The study subject was placed in a sitting position, a bandage was fixed to their pelvis and the thigh of the test side, and the resistance pad was fixed at the end of the 

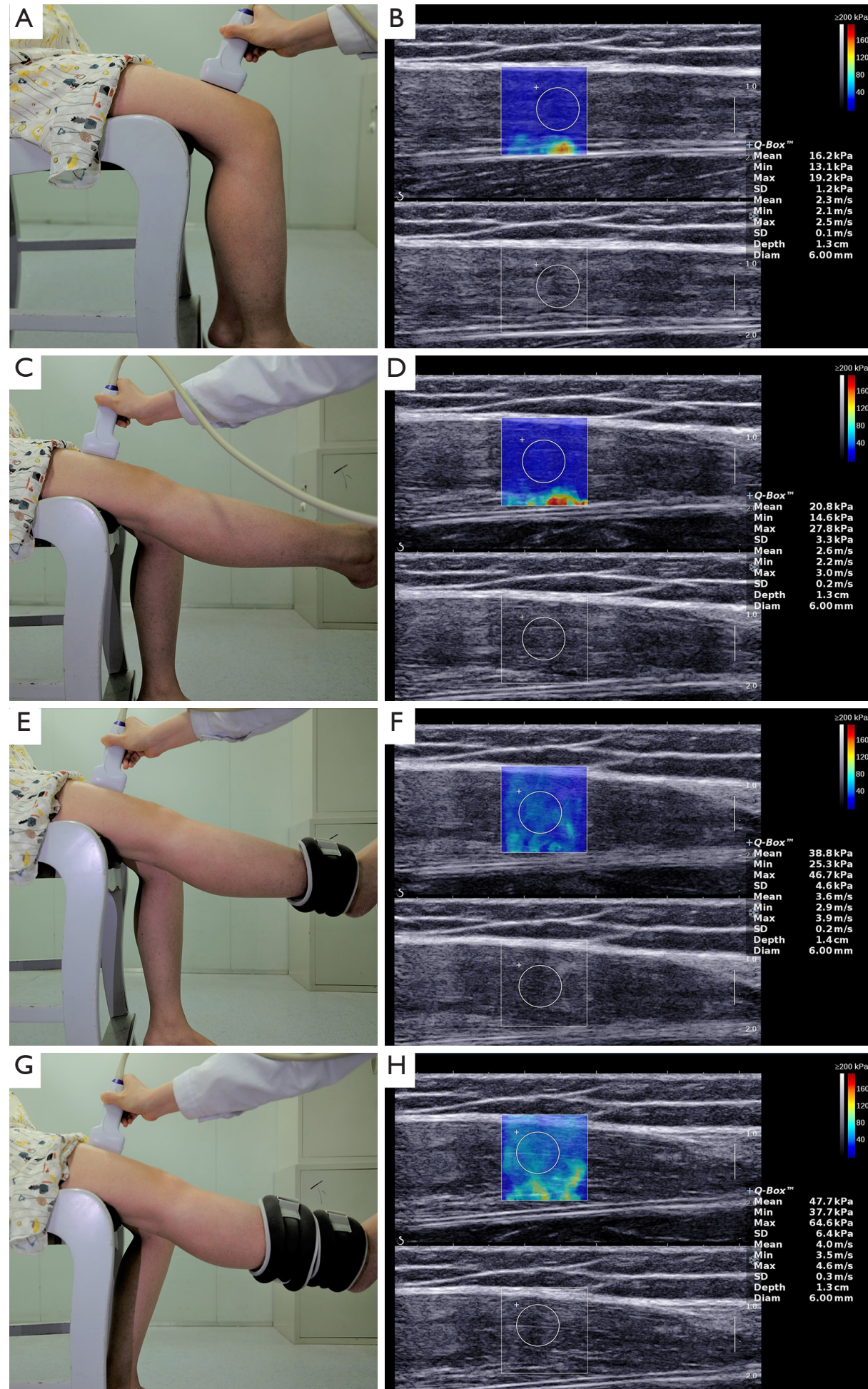

Figure 1 In a study subject, the mean SWV increased from 2.3, 2.6, and $3.6 \mathrm{~m} / \mathrm{s}$ to $4.0 \mathrm{~m} / \mathrm{s}$ in the relaxed position (A, B), tensive position (C, D), under a $1 \mathrm{~kg}$ load (E, F), and under a $2 \mathrm{~kg} \operatorname{load}(\mathrm{G}, \mathrm{H})$. 
Table 1 The demographic characteristics of the study subjects

\begin{tabular}{|c|c|c|c|c|}
\hline Characteristics (mean \pm SD) & All $(n=60)$ & Male $(n=25)$ & Female $(n=35)$ & $\mathrm{P}$ \\
\hline Height, cm & $163.05 \pm 7.90$ & $169.68 \pm 6.00$ & $158.31 \pm 5.24$ & $<0.001$ \\
\hline Weight, kg & $58.96 \pm 8.72$ & $64.60 \pm 8.48$ & $54.02 \pm 5.27$ & $<0.001$ \\
\hline $\mathrm{BMI}, \mathrm{kg} / \mathrm{m}^{2}$ & $22.39 \pm 2.72$ & $22.38 \pm 2.00$ & $22.39 \pm 3.17$ & 0.984 \\
\hline
\end{tabular}

BMI, body mass index.

Table 2 Comparison of SWV in different positions

\begin{tabular}{lccccc}
\hline SWV & Relaxed position & Tensive position & Load $(1 \mathrm{~kg})$ & Load $(2 \mathrm{~kg})$ & All P values \\
\hline Cmax $(\mathrm{m} / \mathrm{s})$ & $2.61 \pm 0.36$ & $3.67 \pm 0.50$ & $4.28 \pm 0.68$ & $4.85 \pm 0.76$ & $<0.001$ \\
Cmin $(\mathrm{m} / \mathrm{s})$ & $1.61 \pm 0.32$ & $2.01 \pm 0.47$ & $2.41 \pm 0.64$ & $2.83 \pm 0.79$ & $<0.001$ \\
Cmean $(\mathrm{m} / \mathrm{s})$ & $2.08 \pm 0.33$ & $2.78 \pm 0.40$ & $3.32 \pm 0.63$ & $3.81 \pm 0.76$ & $<0.001$ \\
\hline
\end{tabular}

$\mathrm{P}<0.001$ was found in comparisons between any two of the above four groups. SWV, shear wave velocity; Cmax, maximum velocities; Cmin, minimum velocities; Cmean, mean velocities.

power arm at the lower one-third of the lower leg of the test side. The motion axis of the knee joint of the test side was kept consistent with the rotation axis of the power arm of the test system. Before performing the knee joint test on each side, five cycles of maximum force knee extension were carried out to familiarize study subjects with the testing process. After 5 minutes, the maximum force knee extension test was commenced and repeated 10 times for each side. During this process, the subjects were encouraged and guided to use the maximum force to conduct the knee extension test. After the test, the instrument recorded the peak torque (PT) (in $\mathrm{Nm}$ ) in the repeated knee extension 10 times, the PT to body weight ratio (PT/BW, in Nm/kg), and total work (TW, in J). Isokinetic muscle testing was performed by professionals.

\section{Statistical analysis}

Statistical analyses were carried out using SPSS 24.0 software (IBM, Armonk, NY, USA). Continuous variables were expressed as mean \pm standard deviation $(\mathrm{SD})$. The $t$-test was used to compare the baseline demographic data between different genders. The comparison of the results of the isokinetic muscle test and SWV between different genders and age groups was conducted using the MannWhitney $\mathrm{U}$ test. The comparison of SWV in four different positions was performed using the Friedman test, and the following pairwise comparisons between the two groups were also conducted using the Kruskal-Wallis test with adjusted $\mathrm{P}$ values. Additionally, correlation analysis was undertaken using the Spearman's correlation test. A twosided $\mathrm{P}$ value of $<0.05$ was considered to be statistically significant.

\section{Results}

This study included 60 healthy volunteers (25 males and 35 females). The demographic characteristics of the study subjects are summarized in Table 1. The participants had a mean age of $35.37 \pm 11.41$ (range, 20-60) years old, and a mean BMI of $22.39 \pm 2.72$ (range, $15.63-28.30$ ) $\mathrm{kg} / \mathrm{m}^{2}$. The heights and weights of the male study subjects were higher than those of the female study subjects. There were no significant differences in age or BMI between males and females, but the average height and weight were greater in males than in females. The study subjects were divided into two groups based on their ages: the 20-34 age group $(n=33)$ and the 35-60 age group $(\mathrm{n}=27)$.

Table 2 shows the results of the comparison of SWV in four different positions, performed using the Friedman test. There were significant differences in the mean, minimum, and maximum SWV between different positions $(\mathrm{P}<0.001)$, and in the following pairwise comparisons, significant differences were also noted between any two groups $(\mathrm{P}<0.001)$. As shown in Figure 2, the SWV showed an increasing trend, in which the greater the impedance, the 


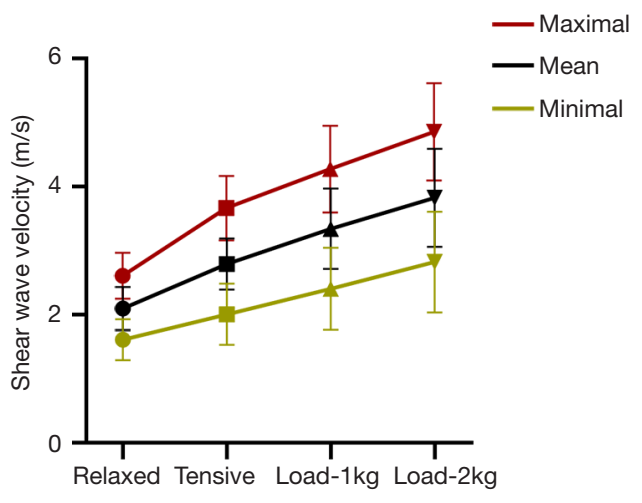

Figure 2 SWV showed an increasing trend. SWV, shear wave velocity. greater the SWV of the working muscle, which indicated greater muscle stiffness.

Table 3 shows the correlations between the values of isokinetic muscle testing (TW, PT and PT/BW) and SWV. In the relaxed position, there was no significant correlation between the SWV and the results of isokinetic muscle testing. With increasing load, the correlation gradually appeared; however, the maximum, minimum, and mean SWV were negatively correlated with the results of isokinetic muscle testing, suggesting that the greater the movement ability of the rectus femoris, the smaller the muscle stiffness under a certain load. Table 4 reveals that in the relaxed position, there were no significant differences in the maximum, minimum, or mean SWV of the rectus

Table 3 Correlation between results of isokinetic muscle testing (TW, PT, and PT/BW) and SWV in four different positions.

\begin{tabular}{|c|c|c|c|c|c|c|c|c|c|c|c|c|}
\hline Variable & \multicolumn{3}{|c|}{ Relaxed position } & \multicolumn{3}{|c|}{ Tensive position } & \multicolumn{3}{|c|}{ Load (1 kg) } & \multicolumn{3}{|c|}{ Load (2 kg) } \\
\hline TW & -0.108 & -0.145 & -0.128 & -0.168 & -0.183 & -0.204 & $-0.279^{\star}$ & $-0.260^{\star}$ & $-0.305^{\star}$ & $-0.278^{\star}$ & -0.117 & -0.195 \\
\hline PT & -0.185 & -0.140 & -0.169 & $-0.299^{\star}$ & $-0.296^{\star}$ & $-0.358^{\star \star}$ & $-0.342^{\star \star}$ & $-0.334^{\star \star}$ & $-0.375^{\star \star}$ & $-0.369^{\star \star}$ & -0.216 & $-0.274^{\star}$ \\
\hline PT/BW & -0.140 & -0.133 & -0.130 & $-0.379^{\star \star}$ & $-0.256^{\star}$ & $-0.392^{\star \star}$ & $-0.366^{\star \star}$ & $-0.258^{\star}$ & $-0.346^{\star \star}$ & $-0.389^{\star \star}$ & -0.198 & $-0.289^{\star}$ \\
\hline
\end{tabular}

* means $\mathrm{P}<0.05$, and ${ }^{*}$ indicates $\mathrm{P}<0.01$. SWV, shear wave velocity; Cmax, maximum velocities; Cmin, minimum velocities; Cmean, mean velocities; TW, total work; PT, peak torque; PT/BW, peak torque to body weight ratio.

Table 4 Differences in isokinetic muscle testing (TW, PT, and PT/BW) and SWV between genders

\begin{tabular}{|c|c|c|c|}
\hline Results & Male & Female & $P$ \\
\hline \multicolumn{4}{|l|}{ SWV (relaxed) } \\
\hline $\mathrm{Cmax}(\mathrm{m} / \mathrm{s})$ & $2.52 \pm 0.28$ & $2.67 \pm 0.40$ & 0.097 \\
\hline $\operatorname{Cmin}(\mathrm{m} / \mathrm{s})$ & $1.58 \pm 0.33$ & $1.64 \pm 0.31$ & 0.964 \\
\hline Cmean (m/s) & $2.06 \pm 0.35$ & $2.09 \pm 0.33$ & 0.540 \\
\hline $\mathrm{Cmax}(\mathrm{m} / \mathrm{s})$ & $3.98 \pm 0.68$ & $4.49 \pm 0.60$ & 0.003 \\
\hline $\operatorname{Cmin}(\mathrm{m} / \mathrm{s})$ & $2.20 \pm 0.63$ & $2.55 \pm 0.61$ & 0.028 \\
\hline Cmean $(\mathrm{m} / \mathrm{s})$ & $3.06 \pm 0.58$ & $3.51 \pm 0.60$ & 0.004 \\
\hline \multicolumn{4}{|c|}{ Isokinetic muscle test } \\
\hline
\end{tabular}

SWV, shear wave velocity; Cmax, maximum velocities; Cmin, minimum velocities; Cmean, mean velocities; TW, total work; PT, peak torque; PT/BW, peak torque to body weight ratio. 
Table 5 Differences in isokinetic muscle testing (TW, PT, and PT/BW) and SWV between different age-based groups

\begin{tabular}{|c|c|c|c|}
\hline Results & 20-34 years old group & 35-60 years old group & $\mathrm{P}$ \\
\hline $\operatorname{Cmax}(\mathrm{m} / \mathrm{s})$ & $2.59 \pm 0.37$ & $2.62 \pm 0.35$ & 0.636 \\
\hline $\operatorname{Cmin}(\mathrm{m} / \mathrm{s})$ & $1.54 \pm 0.32$ & $1.70 \pm 0.30$ & 0.143 \\
\hline Cmean (m/s) & $2.05 \pm 0.33$ & $2.12 \pm 0.34$ & 0.436 \\
\hline $\mathrm{Cmax}(\mathrm{m} / \mathrm{s})$ & $4.11 \pm 0.62$ & $4.47 \pm 0.70$ & 0.045 \\
\hline $\operatorname{Cmin}(\mathrm{m} / \mathrm{s})$ & $2.29 \pm 0.51$ & $2.55 \pm 0.76$ & 0.180 \\
\hline Cmean (m/s) & $3.17 \pm 0.53$ & $3.52 \pm 0.69$ & 0.044 \\
\hline \multicolumn{4}{|c|}{ Isokinetic muscle testing } \\
\hline TW $(J)$ & $757.61 \pm 284.35$ & $544.29 \pm 143.46$ & 0.298 \\
\hline
\end{tabular}

SWV, shear wave velocity; Cmax, maximum velocities; Cmin, minimum velocities; Cmean, mean velocities; TW, total work; PT, peak torque; PT/BW, peak torque to body weight ratio.

Table 6 Correlations between SWV and height, weight, and BMI values

\begin{tabular}{|c|c|c|c|c|c|c|}
\hline Variable & \multicolumn{3}{|c|}{ SWV (relaxed) } & \multicolumn{3}{|c|}{ SWV [load (1 kg)] } \\
\hline Height & -0.244 & -0.180 & -0.197 & $-0.366^{\star *}$ & $-0.342^{\star *}$ & $-0.393^{\star *}$ \\
\hline Weight & -0.244 & -0.121 & -0.186 & -0.147 & $-0.332^{\star \star}$ & $-0.261^{*}$ \\
\hline BMI & -0.108 & 0.038 & -0.047 & 0.110 & -0.172 & -0.015 \\
\hline
\end{tabular}

* means $\mathrm{P}<0.05$, and ${ }^{* *}$ indicates $\mathrm{P}<0.01$. SWV, shear wave velocity; Cmax, maximum velocities; Cmin, minimum velocities; Cmean, mean velocities; BMI, body mass index.

femoris between men and women $(\mathrm{P}>0.05)$; however, under the load of $1 \mathrm{~kg}$, the differences in the maximum, minimum, and mean SWV of rectus femoris between the two genders were statistically significant $(\mathrm{P}<0.05)$. Shear wave velocities of the rectus femoris were greater in women than in men, while the PT, PT/BW, and TW of the quadriceps femoris were markedly greater in men than in women $(\mathrm{P}<0.001)$. As shown in Table 5, in different age groups, the differences in the maximum, minimum, and mean SWV of the rectus femoris muscles were not statistically significant $(\mathrm{P}>0.05)$ in the relaxed position, but under the load of $1 \mathrm{~kg}$, the maximum and mean velocities in the 35-60 age group were significantly greater than those in the 20-34 age group $(\mathrm{P}=0.045$ and $\mathrm{P}=0.044)$. However, the differences in $\mathrm{PT}$, $\mathrm{PT} / \mathrm{BW}$, and TW between these two groups were not all statistically significant. The PT/BW in the $20-34$ age group was greater than that in the $35-60$ age group $(\mathrm{P}=0.012)$, while there were no significant differences in the other parameters between the two groups. Table 6 shows that in the relaxed position, height, weight, and BMI value were not strongly correlated with shear wave velocity (SWV). In contrast, in the tensive position, height and weight were correlated with SWV, with correlation coefficients between -0.261 and -0.393 , indicating a poor correlation. Age and BMI had no significant correlation with SWV.

\section{Discussion}

Muscle strength is closely associated with daily activities and motor function. Therefore, the assessment of muscle strength is of great importance, especially in patients with neuromusculoskeletal disorders $(12,29,30)$. The assessment 
of muscle strength not only provides a basis for clinical diagnosis, but also provides a reference for approaches to treatment and rehabilitation (23,31-33).

In the evaluation of muscle strength, isokinetic muscle testing has significant advantages, such as providing a variety of complex and comprehensive data of a specific muscle or a group of muscles during the entire specified exercise, including PT, PT/BW, average power, time to PT, and TW. Among them, the reliability of PT, PT/BW, and TW has been demonstrated in previous research $(34,35)$. However, isokinetic muscle testing also has disadvantages, such as a complicated operation procedure and limitations in patients with impaired mobility or impaired understanding, as well as the large size of the machine and high costs. Therefore, finding simple, cost-effective, and highly accurate muscle strength testing methods is of great importance.

In recent years, musculoskeletal ultrasound has developed rapidly. UE has been extensively utilized in the diagnosis, treatment evaluation, and rehabilitation prognosis of diseases in various systems of the human body $(13,14,18,26,36)$. In the present study, isokinetic muscle testing, which is commonly considered to be the gold standard in muscle strength assessment methods (34), was selected for correlation analysis with SWE, in which the feasibility and application value of UE for the evaluation of muscle strength were compared.

\section{SWV in different body positions}

The SWV in different body positions were compared. Generally, as the resistance increased, the stiffness of the working muscles increased, and similar to several previous studies, the SWV demonstrated an increasing trend from the relaxed position to the $2 \mathrm{~kg}$ load. Yoshitake et al. (6) pointed out that the elastic modulus of the biceps brachii was linearly correlated with the elbow flexion and muscle contraction strength. Chernak et al. (37) discovered a linear relationship between the SWV of the gastrocnemius muscle during active contraction and passive stretching, and that the SWV increased with the motion of the ankle, from the relaxed position to the maximum dorsiflexion or maximum contraction state. Chen et al. (38) demonstrated that the stiffness of the biceps brachii was higher when the elbow joint was fully straightened than at $30^{\circ}$ flexion. The abovementioned results are consistent with the findings of the present study. However, a number of researchers have arrived at different conclusions. Brandenburg et al. (23) reported that the stiffness of paediatric gastrocnemius muscles is independent of body position, which may be caused by different physiological functions of muscles, or may be related to different body positions.

\section{SWV and isokinetic muscle testing}

Under loading conditions, a stronger correlation was found between the SWV and the PT, the PT/BW, and the TW. Among them, the maximum, minimum, and mean SWV and the PT, PT/BW, and TW of the study subjects were negatively correlated under a load of $1 \mathrm{~kg}$. Our results suggested that the greater the movement ability of the rectus femoris, the less muscle stiffness there was under a certain load. These results are similar to those of a previous study. Leonard et al. (39) reported that during voluntary isometric contractions, the results of myotonometric were negatively correlated with the surface electromyography (sEMG) measurement which represented muscle contractility (40). We hypothesize that the muscle stiffness measured during isometric contraction mainly reflects the level of muscle tension and the extent of muscle contraction (41). The muscles of people who perform better in isokinetic muscle testing are more developed. Under the condition of the same small load, providing the same traction force, the muscle provides less force per unit across the area for those people who have more muscle fibres; therefore, there is less muscle tension and the SWV of the muscle is lower. At the same time, the correlation between the SWV and isokinetic muscle testing measurements indicates that ultrasound has the potential to measure muscle strength or to evaluate muscle contractility.

\section{SWV in different genders and age groups}

Additionally, we compared the SWV and muscle strength of the rectus femoris muscles of study subjects according to different genders and ages. In the relaxed position, there was no significant difference in the maximum, minimum, or mean SWV of the rectus femoris between men and women $(\mathrm{P}>0.05)$. In contrast, under the load of $1 \mathrm{~kg}$, the differences in the maximum, minimum, and mean SWV of rectus femoris between the two genders were statistically significant $(\mathrm{P}<0.05)$, and the SWV of the rectus femoris were greater in women than in men. These results are consistent with those of Eby et al. (1), who found that shear modulus values of biceps brachii in females tended to be higher than in males. In our study, for subjects who 
were in the 20-34 age group and the 35-60 age group, the differences in the maximum, minimum, and mean SWV of the rectus femoris muscles were not statistically significant $(\mathrm{P}>0.05)$ in the relaxed position. However, under the load of $1 \mathrm{~kg}$, the maximum and mean SWV in the 35-60 age group were significantly greater than those in the 20-34 age group $(\mathrm{P}=0.045$ and $\mathrm{P}=0.044$, respectively). The reference range is recommended to be adjusted according to age and gender if SWV becomes a tool to evaluate muscle contractility in the future.

\section{Isokinetic muscle testing in different genders and age groups}

The PT, PT/BW, and TW of the quadriceps femoris were noticeably greater in males than in females $(\mathrm{P}<0.001)$. Among the above-mentioned factors, the PT/BW in the 20-34 age group was higher than that in the 35-60 age group $(\mathrm{P}=0.012)$, while there were no significant differences in PT and TW between the two groups. The results of isokinetic muscle testing reflected the decline in muscle strength with age. In some pathological conditions, such as sarcopenia, ultrasound can detect a decrease in muscle strength via echo intensity or pennation angle, which was previously confirmed in other studies (42-44).

\section{SWV and beight, weight, and BMI}

After correlating different demographic parameters with the SWV of the rectus femoris muscle, we found that in the relaxed position, height, weight, and BMI values were not strongly correlated with SWV. However, in the $1 \mathrm{~kg}$ weight-bearing position, height and weight were correlated with SWV, with correlation coefficients between -0.261 and -0.393 , indicating a poor correlation. Age and BMI were not significantly correlated with SWV. Similarly, Eby et al. (1) studied the stiffness of normal biceps and found that the UE measurement was not associated with BMI or exercise frequency. We therefore speculate that height and weight may influence muscle stiffness and strength to some extent, although whether this effect has a certain regularity calls for further research.

\section{Limitations}

This study has some limitations that need to be discussed. Firstly, no study subjects older than 60 years old were included in the study. Secondly, there was only one measurement site, and further study is therefore required on muscles in other parts of the body. Thirdly, neither ultrasound nor isokinetic strength tests excluded the effects of gravity. Fourthly, the measured values reflected the absolute muscle strength for each individual, and the absence of corrections based on individual differences might have introduced bias in the results. Additionally, the different lengths of the lower limbs, as well as the slight difference in the angle between the lower limbs and the ground when different subjects are tested, may lead to different torque, which may have impacted the results of our study. Lastly, the two measurement methods we compared in this study represent different contraction types, where SWE represents isometric contraction and isokinetic muscle testing represents isokinetic contraction; therefore, the comparability of the data might be limited. Because of the requirement of a relatively static state between the probe and the measured object, it is also difficult to measure the SWV in real time when the limbs are in motion. Consequently, we could not record the realtime SWV of the muscle during the process of isokinetic muscle strength testing. This resulted from the current technical limitations of ultrasonic elastography, which are difficult to address in a short time. Therefore, we believe that in our future research, studying the upper limb muscles and measuring the SWV of the muscles when subjects use a grip dynamometer may be more convincing.

\section{Conclusions}

SWV showed an increasing trend under different conditions; the greater the impedance, the greater the SWV of the working muscle, which indicated greater muscle stiffness. The SWV of muscles and the results of isokinetic muscle testing were correlated during the resistance exercise. Ultrasound has the potential to measure muscle strength, while the specific measurement method requires further adjustment. Additionally, demographic characteristics, such as gender and age, can influence the SWV of muscles. Different reference values should be formulated for different groups of people, or the results should be standardized.

\section{Acknowledgments}

Funding: This study was financially sponsored by the National Natural Science Foundation of China (Grant Nos. 81671696 and 81971622) and the Sichuan Science and 
Technology Program (Grant No. 2019YFS0219).

\section{Footnote}

Conflicts of Interest: All authors have completed the ICMJE uniform disclosure form (available at http://dx.doi. org/10.21037/qims-20-439). The authors have no conflicts of interest to declare.

Ethical Statement: The study was approved by the Ethics Committee of the West China Hospital of Sichuan University. Written informed consent was obtained from each patient for publication of this study and any accompanying images. A copy of the written consent is available for review by the Editor-in-Chief of this journal.

Open Access Statement: This is an Open Access article distributed in accordance with the Creative Commons Attribution-NonCommercial-NoDerivs 4.0 International License (CC BY-NC-ND 4.0), which permits the noncommercial replication and distribution of the article with the strict proviso that no changes or edits are made and the original work is properly cited (including links to both the formal publication through the relevant DOI and the license). See: https://creativecommons.org/licenses/by-nc-nd/4.0/.

\section{References}

1. Eby SF, Cloud BA, Brandenburg JE, Giambini H, Song P, Chen S, LeBrasseur NK, An KN. Shear wave elastography of passive skeletal muscle stiffness: influences of sex and age throughout adulthood. Clin Biomech (Bristol, Avon) 2015;30:22-7.

2. Alfuraih AM, O'Connor P, Tan AL, Hensor EMA, Ladas A, Emery P, Wakefield RJ. Muscle shear wave elastography in idiopathic inflammatory myopathies: a case-control study with MRI correlation. Skeletal Radiol 2019;48:1209-19.

3. Alfuraih AM, Tan AL, O'Connor P, Emery P, Wakefield RJ. The effect of ageing on shear wave elastography muscle stiffness in adults. Aging Clin Exp Res 2019;31:1755-63.

4. Chan ST, Fung PK, Ng NY, Ngan TL, Chong MY, Tang $\mathrm{CN}, \mathrm{He}$ JF, Zheng YP. Dynamic changes of elasticity, cross-sectional area, and fat infiltration of multifidus at different postures in men with chronic low back pain. Spine J 2012;12:381-8.

5. Shinohara M, Sabra K, Gennisson JL, Fink M, Tanter M. Real-time visualization of muscle stiffness distribution with ultrasound shear wave imaging during muscle contraction.
Muscle Nerve 2010;42:438-41.

6. Yoshitake Y, Takai Y, Kanehisa H, Shinohara M. Muscle shear modulus measured with ultrasound shear-wave elastography across a wide range of contraction intensity. Muscle Nerve 2014;50:103-13.

7. Davidson MJ, Nielsen PMF, Taberner AJ, Kruger JA. Is it time to rethink using digital palpation for assessment of muscle stiffness? Neurourol Urodyn 2020;39:279-85.

8. Bensamoun SF, Ringleb SI, Chen Q, Ehman RL, An KN, Brennan M. Thigh muscle stiffness assessed with magnetic resonance elastography in hyperthyroid patients before and after medical treatment. J Magn Reson Imaging 2007;26:708-13.

9. Debernard L, Robert L, Charleux F, Bensamoun SF. Analysis of thigh muscle stiffness from childhood to adulthood using magnetic resonance elastography (MRE) technique. Clin Biomech (Bristol, Avon) 2011;26:836-40.

10. Kennedy P, Barnhill E, Gray C, Brown C, van Beek EJR, Roberts N, Greig CA. Magnetic resonance elastography (MRE) shows significant reduction of thigh muscle stiffness in healthy older adults. Geroscience 2020;42:311-21.

11. Bercoff J, Tanter M, Fink M. Supersonic shear imaging: a new technique for soft tissue elasticity mapping. IEEE Trans Ultrason Ferroelectr Freq Control 2004;51:396-409.

12. Walker FO. Neuromuscular ultrasound. Neurol Clin 2004;22:563-90, vi.

13. Pillen S, van Alfen N. Skeletal muscle ultrasound. Neurol Res 2011;33:1016-24.

14. Dinnes J, Bamber J, Chuchu N, Bayliss SE, Takwoingi Y, Davenport C, Godfrey K, O'Sullivan C, Matin RN, Deeks JJ, Williams HC. High-frequency ultrasound for diagnosing skin cancer in adults. Cochrane Database Syst Rev 2018;12:Cd013188.

15. Garra BS. Imaging and estimation of tissue elasticity by ultrasound. Ultrasound Q 2007;23:255-68.

16. Oberai AA, Gokhale NH, Goenezen S, Barbone PE, Hall TJ, Sommer AM, Jiang J. Linear and nonlinear elasticity imaging of soft tissue in vivo: demonstration of feasibility. Phys Med Biol 2009;54:1191-207.

17. Săftoiu A, Gilja OH, Sidhu PS, Dietrich CF, Cantisani V, Amy D, Bachmann-Nielsen M, Bob F, Bojunga J, Brock M, Calliada F, Clevert DA, Correas JM, D'Onofrio M, Ewertsen C, Farrokh A, Fodor D, Fusaroli P, Havre RF, Hocke M, Ignee A, Jenssen C, Klauser AS, Kollmann C, Radzina M, Ramnarine KV, Sconfienza LM, Solomon C, Sporea I, Stefanescu H, Tanter M, Vilmann P. The EFSUMB Guidelines and Recommendations 
for the Clinical Practice of Elastography in NonHepatic Applications: Update 2018. Ultraschall Med 2019;40:425-53.

18. Suvannarerg V, Chitchumnong $\mathrm{P}$, Apiwat $\mathrm{W}$, Lertdamrongdej L, Tretipwanit N, Pisarnturakit P, Sitthinamsuwan P, Thiravit S, Muangsomboon K, Korpraphong P. Diagnostic performance of qualitative and quantitative shear wave elastography in differentiating malignant from benign breast masses, and association with the histological prognostic factors. Quant Imaging Med Surg 2019;9:386-98.

19. Song Y, Zhang TJ, Li Y, Gao Y. Application of real-time shear wave elastography in the assessment of torsional cervical dystonia. Quant Imaging Med Surg 2019;9:662-70.

20. Zhu S, Lin W, Chen S, Qi H, Wang S, Zhang A, Cai J, Lai B, Sheng Y, Ding G. The correlation of muscle thickness and pennation angle assessed by ultrasound with sarcopenia in elderly Chinese community dwellers. Clin Interv Aging 2019;14:987-96.

21. Cho KH, Lee HJ, Lee WH. Intra- and inter-rater reliabilities of measurement of ultrasound imaging for muscle thickness and pennation angle of tibialis anterior muscle in stroke patients. Top Stroke Rehabil 2017;24:368-73.

22. Gennisson JL, Cornu C, Catheline S, Fink M, Portero P. Human muscle hardness assessment during incremental isometric contraction using transient elastography. $\mathrm{J}$ Biomech 2005;38:1543-50.

23. Brandenburg JE, Eby SF, Song P, Zhao H, Brault JS, Chen $\mathrm{S}$, An KN. Ultrasound elastography: the new frontier in direct measurement of muscle stiffness. Arch Phys Med Rehabil 2014;95:2207-19.

24. Yavuz A, Bora A, Bulut MD, Batur A, Milanlioglu A, Göya C, Andic C. Acoustic Radiation Force Impulse (ARFI) elastography quantification of muscle stiffness over a course of gradual isometric contractions: a preliminary study. Med Ultrason 2015;17:49-57.

25. Catalano O, Siani A. Cutaneous melanoma: role of ultrasound in the assessment of locoregional spread. Curr Probl Diagn Radiol 2010;39:30-6.

26. Lassau N, Lamuraglia M, Koscielny S, Spatz A, Roche A, Leclere J, Avril MF. Prognostic value of angiogenesis evaluated with high-frequency and colour Doppler sonography for preoperative assessment of primary cutaneous melanomas: correlation with recurrence after a 5 year follow-up period. Cancer Imaging 2006;6:24-9.

27. Morrow DA, Haut Donahue TL, Odegard GM, Kaufman KR. Transversely isotropic tensile material properties of skeletal muscle tissue. J Mech Behav Biomed Mater 2010;3:124-9.

28. Dubois $G$, Kheireddine W, Vergari C, Bonneau D, Thoreux P, Rouch P, Tanter M, Gennisson JL, Skalli W. Reliable protocol for shear wave elastography of lower limb muscles at rest and during passive stretching. Ultrasound Med Biol 2015;41:2284-91.

29. Cook JD, Glass DS. Strength evaluation in neuromuscular disease. Neurol Clin 1987;5:101-23.

30. Cadore EL, Pinto RS, Alberton CL, Pinto SS, Lhullier FL, Tartaruga MP, Correa CS, Almeida AP, Silva EM, Laitano O, Kruel LF. Neuromuscular economy, strength, and endurance in healthy elderly men. J Strength Cond Res 2011;25:997-1003.

31. Büyükvural Şen S, Ozbudak Demir S, Ekiz T, Ozgirgin N. Effects of the bilateral isokinetic strengthening training on functional parameters, gait, and the quality of life in patients with stroke. Int J Clin Exp Med 2015;8:16871-9.

32. Czaplicki A, Jarocka M, Walawski J. Isokinetic Identification of Knee Joint Torques before and after Anterior Cruciate Ligament Reconstruction. PLoS One 2015;10:e0144283.

33. Durmus B, Emre S, Sahin N, Karincaoglu Y, Dogan E, Baysal O, Ersoy Y, Altay Z. Isokinetic Evaluation of Knee Extensor/Flexor Muscle Strength in Behcet's Patients. Acta Reumatol Port 2015;40:348-54.

34. Bosquet L, Gouadec K, Berryman N, Duclos C, Gremeaux V, Croisier JL. The Total Work Measured During a High Intensity Isokinetic Fatigue Test Is Associated With Anaerobic Work Capacity. J Sports Sci Med 2016;15:126-30.

35. Törpel A, Becker T, Thiers A, Hamacher D, Schega L. Intersession Reliability of Isokinetic Strength Testing in Knee and Elbow Extension and Flexion Using the BTE PrimusRS. J Sport Rehabil 2017;26(4).

36. Zhou M, Du H, Ying T, Shui W, Dou C. Value of high-frequency two-dimensional ultrasound on evaluating puborectalis muscle. Arch Gynecol Obstet 2020;301:1347-52.

37. Chernak LA, DeWall RJ, Lee KS, Thelen DG. Length and activation dependent variations in muscle shear wave speed. Physiol Meas 2013;34:713-21.

38. Chen J, O’Dell M, He W, Du LJ, Li PC, Gao J. Ultrasound shear wave elastography in the assessment of passive biceps brachii muscle stiffness: influences of sex and elbow position. Clin Imaging 2017;45:26-9.

39. Leonard CT, Brown JS, Price TR, Queen SA, Mikhailenok EL. Comparison of surface electromyography and 
myotonometric measurements during voluntary isometric contractions. J Electromyogr Kinesiol 2004;14:709-14.

40. Disselhorst-Klug C, Schmitz-Rode T, Rau G. Surface electromyography and muscle force: limits in sEMG-force relationship and new approaches for applications. Clin Biomech (Bristol, Avon) 2009;24:225-35.

41. Murayama M, Watanabe K, Kato R, Uchiyama T, Yoneda T. Association of muscle hardness with muscle tension dynamics: a physiological property. Eur J Appl Physiol 2012;112:105-12.

42. Kawai H, Kera T, Hirayama R, Hirano H, Fujiwara Y, Ihara K, Kojima M, Obuchi S. Morphological and qualitative characteristics of the quadriceps muscle of

Cite this article as: Tang X, Wang L, Guo R, Huang S, Tang Y, Qiu L. Application of ultrasound elastography in the evaluation of muscle strength in a healthy population. Quant Imaging Med Surg 2020;10(10):1961-1972. doi: 10.21037/qims-20-439 community-dwelling older adults based on ultrasound imaging: classification using latent class analysis. Aging Clin Exp Res 2018;30:283-91.

43. Sanabria SJ, Martini K, Freystatter G, Ruby L, Goksel O, Frauenfelder T, Rominger MB. Speed of sound ultrasound: a pilot study on a novel technique to identify sarcopenia in seniors. Eur Radiol 2019;29:3-12.

44. Watanabe Y, Yamada Y, Fukumoto Y, Ishihara T, Yokoyama K, Yoshida T, Miyake M, Yamagata E, Kimura M. Echo intensity obtained from ultrasonography images reflecting muscle strength in elderly men. Clin Interv Aging 2013;8:993-8. 